\title{
PENGARUH TEKANAN INJEKSI BAHAN BAKAR TERHADAP KARAKTERISTIK KABUTAN CAMPURAN SOLAR DAN DIMETIL ETER
}

\author{
Bambang Suwondo Rahardjo dan Taufik Yuwono \\ Pusat Teknologi Pengembangan Sumberdaya Energi \\ BPPT Gedung II Lantai 22 JI MH Thamrin No.8 Jakarta 10340 \\ E-mail: bamsr52@yahoo.com
}

\begin{abstract}
Fuel spray injection plays a main role in determining the performance of diesel engines, where the spray pattern illustrates fuel combustion occurs in the combustion chamber. Characteristics of Sauter Mean Diameter (SMD) spray is devoted to fuel evaporation, and mixing and combustion quality affected by pressure injection $(\Delta P)$ and the physical chemical properties of the fuel (density, surface tension, viscosity and boiling point). From fuel spray test results showed that fuel evaporation characteristics of fuel at a certain pressure effect on engine performance. The higher the injection pressure will reduce the diameter of the fuel sprays after injection (SMD), thus speeding up evaporation and mixing processes between fuel and air in the combustion chamber with resulted the combustion process is more completely
\end{abstract}

Kata kunci: characteristics of fuel spray, diesel fuel, DME.

\section{PENDAHULUAN}

Upaya pengembangan bahan bakar alternatif sebagai pengganti bahan bakar minyak (BBM) menjadi tuntutan yang semakin menguat, di mana pertimbangan untuk menjadikan bahan bakar alternatif baru adalah bahan bakar yang memiliki dampak terhadap masyarakat, antara lain dampak gas rumah kaca yang dihasilkan, jumlah cadangan, ketersediaan, kemudahan dan kesesuaian penggunaan pada sektor transportasi maupun sektor lain, infrastruktur, ekonomis, serta aman (Troy A. Semelsberger, 2006).

Di-methyl ether (DME) adalah senyawa eter paling sederhana dengan rumus kimia $\mathrm{CH}_{3} \mathrm{OCH}_{3}$ dikenal sebagai pelarut organik dan media ekstraksi dalam bentuk cairan aerosol yang tak berwarna untuk keperluan industri propelan. DME sebagai propelan banyak digunakan sebagai salah satu bahan pendorong dalam industri parfum, obat pembasmi nyamuk, personal care (hair sprays, foams, shaving cream, antiperspirants), colognes, pengharum, bahan pendingin makanan, industri coating, cat dan finishing maupun otomotif.

Pada kondisi suhu lingkungan dan tekanan atmosfer berwujud gas tak berwarna yang mempunyai sifat menyerupai propana $\left(\mathrm{C}_{3} \mathrm{H}_{8}\right)$ dan LPG. Sedangkan pada kondisi suhu ruang dengan tekanan 6 atm atau pada tekanan atmosfer dengan suhu $-25^{\circ} \mathrm{C}$ berwujud cairan tidak berwarna yang dapat diangkut dan disimpan dalam tangki pada suhu rendah seperti LPG (Myung Yoon Kim, 2008).

DME sangat mudah terbakar, tanpa menimbulkan jelaga dalam kondisi apapun karena atom oksigen yang terdapat dalam molekul. DME juga merupakan bahan kimia tidak beracun atau senyawa yang tidak mengandung sulfur (S) dan nitrogen (N) sehingga emisi (SOx, NOx, partikulat dan jelaga) jauh lebih rendah daripada diesel (solar) dan tidak merusak lapisan ozon. Selain itu, DME tidak korosif terhadap logam sehingga tidak memerlukan modifikasi khusus terhadap infrastruktur LPG yang ada jika digunakan sebagai pengganti atau pencampur LPG (Constantine Arcoumanis, 2008),

Pada fraksi mol yang rendah (\%volume yang rendah) gas ini memiliki aroma yang sangat kuat dan bahkan fraksi mol yang tinggi sekalipun (>10\%volume) tidak memiliki efek pada kesehatan, kecuali efek narkotika setelah menghirup dalam jangka waktu yang lama, namun itupun dapat dikenali dari baunya.

DME mempunyai nilai kalor lebih rendah daripada $L P G$ maupun $L N G$ atau $\pm 65 \%$ dari gas alam $\left(\mathrm{CH}_{4}\right)$ atau $\pm 40 \%$ dari metanol $(\mathrm{MeOH})$, 
dikarenakan perbedaan struktur kimia, namun berat jenis cair DME lebih besar sehingga total nilai kalor sebuah tangki DME $\pm 90 \%$ dari tangki serupa untuk LPG. Cetane Number (CN) DME tinggi (55 60) adalah ukuran kualitas pembakaran bahan bakar solar selama penyalaan kompresi, sehingga dapat digunakan sebagai bahan bakar pengganti solar.

Saat ini DME sedang diproyeksikan sebagai salah satu sumber bahan bakar alternatif ramah lingkungan, yang dapat dihasilkan dari syngas berbagai sumberdaya energi, seperti batubara, biomasa dan gas alam. Syngas dapat dihasilkan melalui proses gasifikasi batubara/biomassa atau proses oksidasi parsial/steam methane reforming/auto-thermal reforming dari gas alam. Proses pembuatan DME ada dua cara yaitu proses secara langsung (direct process) dan proses tidak langsung (indirect process). Proses langsung adalah proses pembentukan syngas $\left(\mathrm{H}_{2}+\mathrm{CO}\right)$ yang dapat dihasilkan melalui proses gasifikasi batubara/biomassa atau proses oksidasi parsial gas alam, kemudian disintesa menjadi DME. Sedangkan proses tidak langsung adalah proses yang diawali dengan pembuatan metanol $(\mathrm{MeOH})$, diikuti dehidrasi metanol $(\mathrm{MeOH})$ dalam reaktor terpisah disintesa menjadi DME.

Pemanfaatan DME berarti telah meningkatkan nilai ekonomisnya dan sebagai salah satu upaya mengurangi ketergantungan terhadap BBM sekaligus memecahkan masalah pencemaran lingkungan. Ditinjau dari perbandingan harga bahan bakar, DME masih kompetitif dibandingkan LPG maupun bahan bakar diesel. Pada basis kesetaraan energi, biaya produksi DME lebih rendah daripada solar. Namun adanya perbedaan karakteristik antara solar dan DME menyebabkan penggunaan DME sebagai bahan bakar pada mesin diesel membutuhkan modifikasi sistem injeksi yang sudah ada. Pembakaran DME tidak mengeluarkan jelaga karena mengandung oksigen dan struktur kimia tanpa membentuk ikatan-ikatan karbon.

Kelebihan yang dimiliki DME menunjukkan potensi menjadi bahan bakar alternatif pada mesin diesel, sedangkan kekurangannya untuk dapat diaplikasikan merupakan tantangan yang harus dijawab melalui penelitian.

\section{METODOLOGI}

Uji pengkabutan bahan bakar solar, DME dan campuran solar+DME dilakukan di Laboratorium Balai Teknologi Motor dan Propolsi (BTMP), PUSPIPTEK, Serpong.

\subsection{Tujuan}

Melakukan uji pengkabutan bahan bakar solar, DME dan campuran solar+DME pada variasi tekanan untuk mengetahui karakteristik pembakaran di ruang bakar

\subsection{Peralatan}

Gambar 1 menunjukkan peralatan uji pengkabutan bahan bakar solar, DME dan campurannya, yang terdiri dari tangki bahan bakar, tabung gas nitrogen $\left(\mathrm{N}_{2}\right)$, diesel injection tester, diesel injector multi-hole, dan background screen.

Tangki bahan bakar (1) sebagai tempat penyimpanan (DME, solar atau campuran solar+DME) berasal dari tabung LPG yang dimodifikasi pada bagian bawah yaitu dibuatkan "kaki-kaki" agar katup dan napple yang berada di bawah tangki sebagai tempat mengalirnya bahan bakar tidak terhimpit.

Tabung gas $\mathrm{N}_{2}$ (2) untuk memberikan tekanan tangki bahan bakar di atas 5 bar $\left(20^{\circ} \mathrm{C}\right)$ agar DME menjadi fase cair supaya bisa bercampur sempurna dengan solar, dan menjaga tekanan pasokan DME ke diesel injection tester tetap tinggi.

Diesel injection tester (3) merk: Bosch, tipe: EFEP $60 \mathrm{H}$, tekanan: $40 \mathrm{MPa}$ untuk uji pengkabutan bahan bakar.

Diesel injector berlubang banyak (5 lubang) tipe direct injection (4) mobil isuzu Panther $2500 \mathrm{cc}$ dengan tekanan max.18,5 MPa.

Backgorund screen berupa kain berwarna biru (5) agar dalam pengambilan gambar pola kabutan bahan bakar saat keluar dari injektor dengan menggunakan video camera digital dapat terlihat jelas.

\subsection{Bahan}

Tabel 1 dan Tabel 2 masing-masing menunjukkan karakteristik bahan bakar uji DME dan diesel (solar).

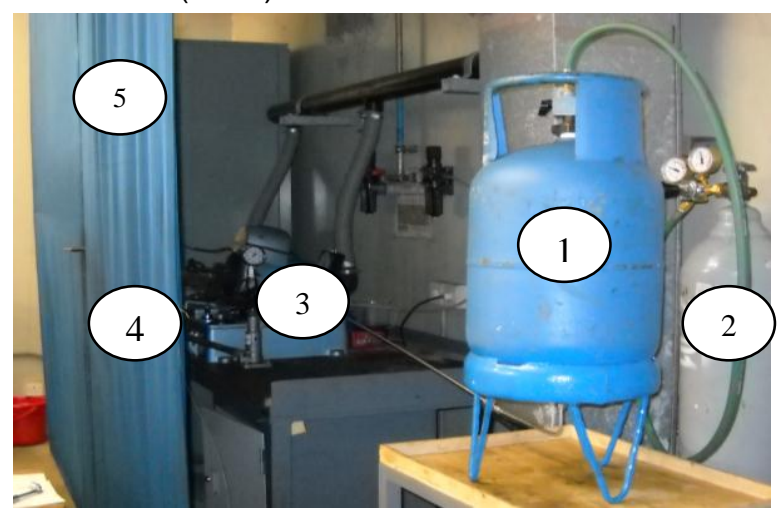

Gambar 1. Peralatan uji pengkabutan bahan bakar 


\subsection{Metode}

Pengujian pengkabutan bahan bakar dalam rangka pelaksanaan penelitian telah dilakukan di BTMP dengan mengkikuti tahapan sebagai berikut.

- Memasang peralatan uji tekanan bukaan nozzle.

- Menetapkan tekanan bukaan nozzle pada pressure gauge dengan mengatur kontraksi pegas injektor.

- Memposisikan injektor pada lubang di background screen.

- Menekan tuas pompa ke arah bawah untuk memulai pengujian.

- Mengambil foto atau merekam gambar perubahan pola kabutan bahan bakar menggunakan video camera digital agar dapat teramati secara jelas.

- Setelah pengujian selesai, melepas tubing penghubung dari pompa ke injektor, lalu mengosongkan bahan bakar di dalamnya untuk menyiapkan pengujian pengkabutan bahan bakar berikutnya.

- Mengulangi tahapan tersebut untuk pengujian dengan variasi bahan bakar maupun variasi tekanan pengkabutan

\section{HASIL DAN PEMBAHASAN}

Secara umum karakteristik pembakaran dipengaruhi oleh dua parameter penting, yaitu: (i) tekanan injeksi $(\Delta \mathrm{P})$ dan sifat kimia fisik bahan bakar (densitas, tegangan permukaan, viskositas dan titik didih). Pada saat awal injeksi ( $\left.t_{\text {asoi }} \leq t_{b}\right)$, jarak atau panjang penetrasi kabutan (S) dipengaruhi oleh tekanan injeksi $(\Delta P)$ dan densitas bahan bakar $\left(\rho_{l}\right)$, seperti dirumuskan menurut persamaan [1].

$$
t_{\text {asoi }} \leq t_{b}: S=0.39 \sqrt{\left(\frac{2 \Delta P}{\rho_{l}}\right)} t_{\text {asoi }}
$$

Persamaan [2] menunjukkan rumus empiris untuk jarak atau panjang penetrasi kabutan (S) setelah proses injeksi selesai $\left(t_{a s o i} \geq t_{b}\right)$, di mana pengaruh tekanan injeksi dan sifat kimia fisik bahan bakar mengecil bahkan tidak ada sama sekali, sementara pengaruh densitas udara sekitar membesar.

$$
\begin{gathered}
t_{\text {asoi }} \geq t_{b}: S=2.95\left(\frac{\Delta P}{\rho_{g}}\right)^{0.25} \sqrt{D\left(t_{\text {asoi }}\right)} \text { [2] } \\
\text { di mana }: t_{b}=\frac{28.65 \rho_{l} D}{\sqrt{\rho_{g} \Delta P}}
\end{gathered}
$$

Karakteristik pengkabutan SMD (Sauter Mean Diameter) dikhususkan untuk penguapan bahan bakar, pencampuran dan kualitas pembakaran, juga dipengaruhi oleh tekanan injeksi $(\Delta \mathrm{P})$ dan sifat kimia fisik bahan bakar, seperti yang dirumuskan menurut persamaan [3].

$$
\begin{aligned}
S M D=6156 & v_{m}^{0.385} \gamma_{m}^{0.737} \rho_{m}^{0.737} \rho_{A}^{0.06} \Delta P_{L}^{-0.54}[3] \\
\rho_{\mathrm{m}}: & \text { Densitas } \\
v_{\mathrm{m}}: & \text { Viskositas } \\
\gamma_{\mathrm{m}}: & \text { Tegangan permukaan } \\
\rho_{\mathrm{A}}: & \text { Densitas udara ambient } \\
\Delta \mathrm{P}_{\mathrm{L}}: & \text { Tekanan injeksi pengkabutan }
\end{aligned}
$$

Berdasarkan hasil rekaman gambar menggunakan video camera digital dapat ditunjukkan interaksi atau pengaruh tekanan injeksi dan sifat kimia fisik bahan bakar terhadap karakteristik pengkabutan bahan bakar.

\subsection{Hasil}

Gambar 2, Gambar 3, dan Gambar 4 masingmasing menunjukkan pola kabutan bahan bakar $100 \%$ solar, campuran solar+DME 50/50, dan 100\%DME pada tekanan 150 bar.



Gambar 2. Pola kabutan $100 \%$ solar (150 bar)

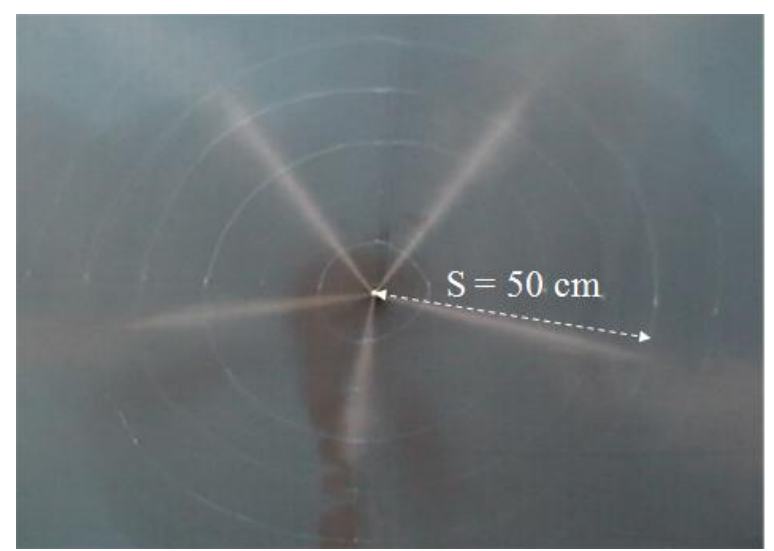

Gambar 3 Pola kabutan 100\% solar (150 bar) 


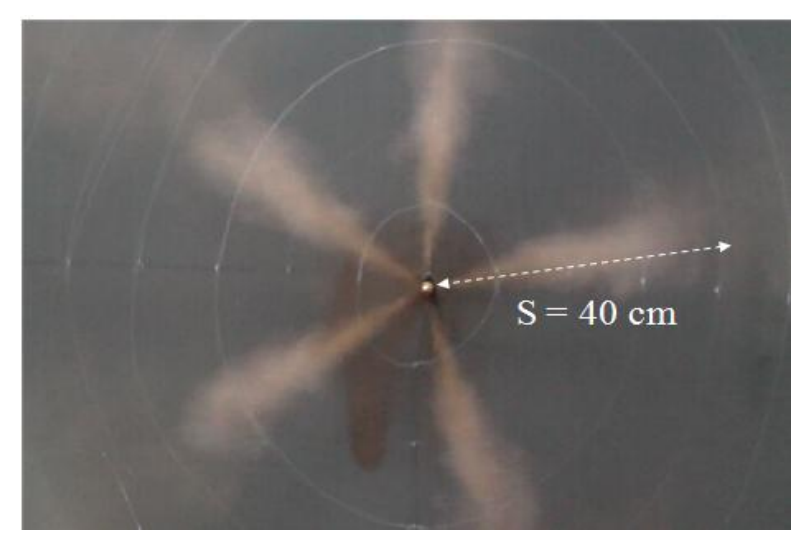

Gambar 4. Pola kabutan campuran solar+DME 50/50 (150 bar)

Gambar 5, Gambar 6, dan Gambar 7 masing-masing menunjukkan pola kabutan bahan bakar $100 \%$ solar, campuran solar+DME 50/50, dan 100\%DME pada tekanan 180 bar.

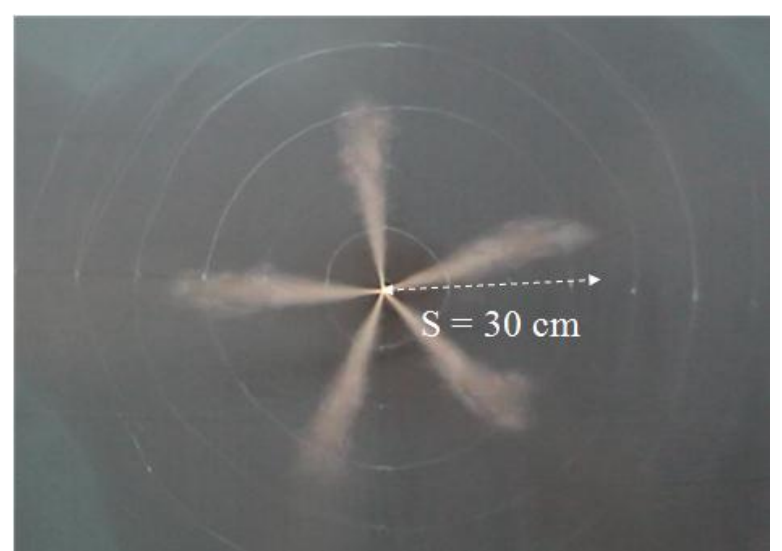

Gambar 5. Pola kabutan 100\%DME (150 bar)

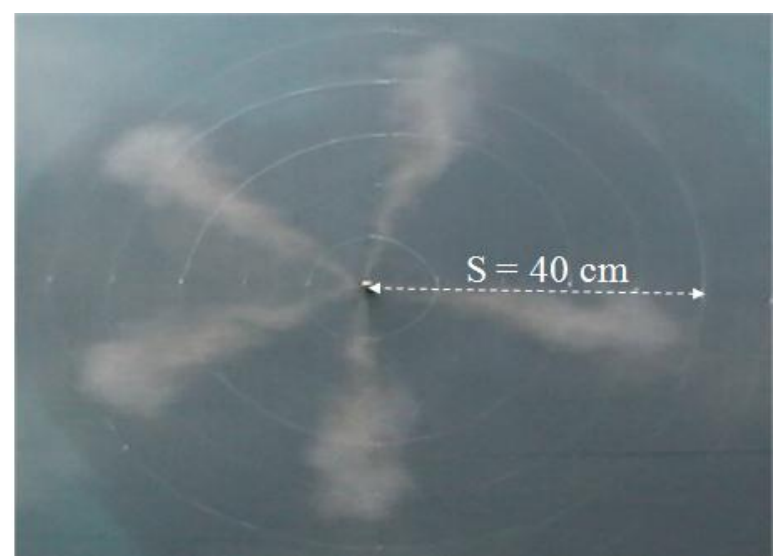

Gambar 6. Pola kabutan campuran solar+DME 50/50 (180 bar)



Gambar 7. Pola kabutan $100 \%$ DME (180 bar)

Gambar 8, Gambar 9, dan Gambar 10 masing-masing menunjukkan pola kabutan bahan bakar $100 \%$ solar, campuran solar+DME 50/50, dan 100\%DME pada tekanan 235 bar.

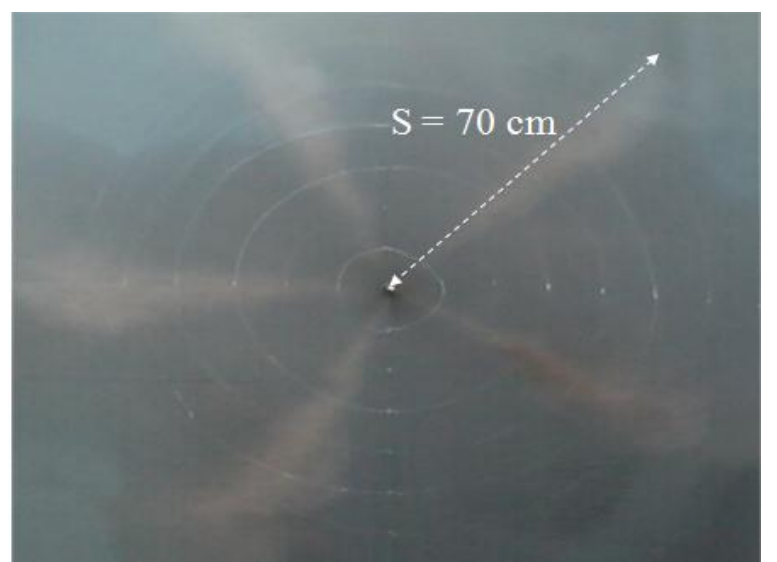

Gambar 8 . Pola kabutan 100\% solar (235 bar)






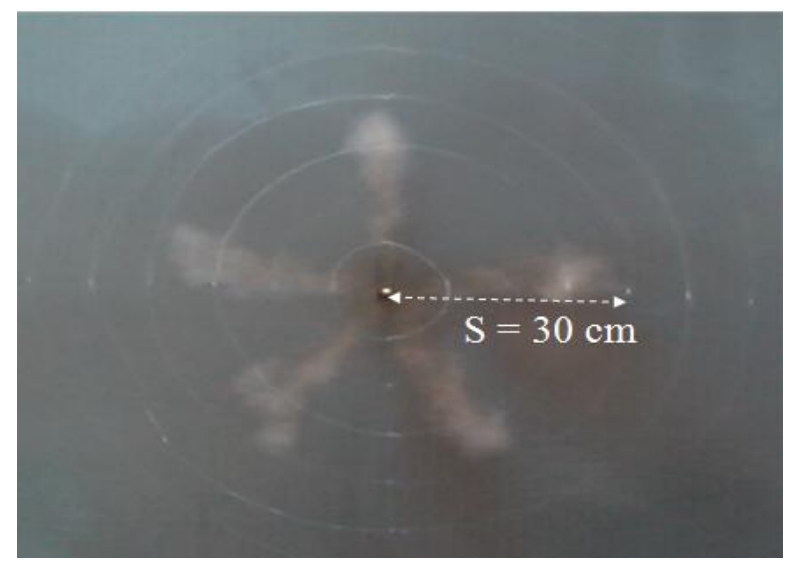

Gambar 10. Pola kabutan 100\%DME (235 bar)

\subsection{Pembahasan}

\subsubsection{Karakteristik pengkabutan bahan bakar pada tekanan 150 bar}

Pada tekanan 150 bar, jarak penetrasi kabutan (S) dari bahan bakar $100 \%$ solar adalah terpanjang $(50 \mathrm{~cm})$, sedangkan bahan bakar campuran $50 \%$ solar+50\%DME sekitar $40 \mathrm{~cm}$ dan untuk bahan bakar $100 \%$ DME adalah terpendek $(30 \mathrm{~cm})$. Perbedaan jarak penetrasi kabutan $(\mathrm{S})$ tersebut disebabkan oleh titik didih DME $\left(-25^{\circ} \mathrm{C}\right.$, 1 atm) yang jauh lebih rendah dari solar (150$380^{\circ} \mathrm{C}$, $1 \mathrm{~atm}$ ), sehingga DME lebih mudah menguap dan cenderung mudah terdistribusi ke samping atau bergerak melebar. Butiran solar dengan titik didih yang lebih tinggi akan lebih stabil bergerak secara linier mengikuti arah tekanan injeksi dan cenderung bergerak lurus, sehingga mengakibatkan jarak penetrasi kabutan (S) lebih panjang (Elana M. Chapman, et al., 2003). Dengan demikian semakin tinggi kandungan DME jarak penetrasi kabutan (S) akan semakin pendek.

Kecenderungan lain yang timbul adalah semakin tinggi kandungan DME dalam solar semakin lebar sudut kabutan yang terbentuk, hal ini terkait dengan gerakan uap dari molekul DME dan solar ke arah samping. Semakin tinggi kandungan DME dalam campuran menjadikan proses pencampuran bahan bakar dan udara lebih sempurna sehingga pembakaran akan terjadi lebih sempurna, hal ini disebabkan oleh karena pembentukan uap lebih cepat dan lebih banyak pada awal pengkabutan.

\subsubsection{Karakteristik Pengkabutan Bahan Bakar pada Tekanan 180 bar}

Pada tekanan injeksi yang lebih tinggi yaitu sekitar 180 bar, jarak penetrasi kabutan (S) masih relatif sama dengan tekanan injeksi 150 bar. Namun demikian tekanan injeksi mempengaruhi diameter butiran bahan bakar setelah diinjeksi (SMD) terutama pada kondisi ruangan (ambient). Tekanan injeksi semakin tinggi akan memperkecil diameter butiran bahan bakar setelah diinjeksi sehingga memudahkan atau mempercepat penguapan.

Gambar 5 menunjukkan bahwa pola kabut dari solar $100 \%$ lebih melebar/menyebar yang ditunjukkan dengan sudut pengkabutan $(\alpha)$ lebih besar dibandingkan pada tekanan injeksi 150 bar pada Gambar 2. Pada Gambar 6 dan Gambar 7 menunjukkan bahwa semakin tinggi kandungan DME maka tingkat penguapan semakin cepat, begitu juga sudut pengkabutan $\alpha$ semakin besar. Proses pencampuran antara bahan bakar dan udara di dalam ruang bakar, semakin membaik pada tekanan injeksi 180 bar dibandingkan pada tekanan 150 bar.

\subsubsection{Karakteristik Pengkabutan Bahan Bakar pada Tekanan 235 bar}

Pada tekanan 235 bar, karakteristik pengkabutan bahan bakar akan berubah tingkat penyebarannya secara signifikan, hal ini karena diameter butiran solar akan semakin mengecil, sehingga tingkat penguapan akan semakin cepat. Jarak penetrasi kabutan (S) pada pengkabutan bahan bakar $100 \%$ solar masih dipengaruhi oleh tekanan injeksi (Gambar 8), namun demikian pengaruh tekanan injeksi tidak terlalu signifikan pada bahan bakar campuran 50\%solar+50\%DME (Gambar 9) maupun 100\%DME (Gambar 10). Tekanan injeksi akan lebih dominan berpengaruh pada tingkat penyebaran kabut (sudut $\alpha$ ) dan tingkat penguapan bahan bakar bakar (Hyun K. Suh, Chang S. Lee, 2007).. Proses pencampuran maupun proses pembakaran antara DME dengan udara akan semakin membaik pada tekanan injeksi yang lebih tinggi.

\section{KESIMPULAN}

Telah dilaksanakan pengujian karakteristik pengkabutan bahan bakar solar, DME dan campurannya pada variasi tekanan injeksi 150 , 180 dan 235 bar menggunakan injektor mobil diesel isuzu Panther 2500cc tipe direct injection. Dari kegiatan tersebut dapat disimpulkan sebagai berikut.

Hasil rekaman gambar menunjukkan interaksi atau pengaruh tekanan injeksi dan sifat kimia fisik bahan bakar terhadap karakteristik pengkabutan bahan bakar.

Pada tekanan 235 bar, jarak penetrasi kabutan (S) bahan bakar 100\%solar adalah terpanjang $(70 \mathrm{~cm})$, kemudian bahan bakar campuran $50 \%$ solar+50\%DME sekitar $40 \mathrm{~cm}$ dan bahan bakar 100\%DME adalah terpendek 
$(30 \mathrm{~cm})$. Sementara jarak penetrasi kabutan (S) bahan bakar pada tekanan injeksi 150 bar dan 180 bar, menunjukkan sama, yaitu $50 \mathrm{~cm}(100 \%$ Solar), $40 \mathrm{~cm}$ (50\%Solar+50\%DME), dan $30 \mathrm{~cm}$ (100\%DME).

Perbedaan jarak penetrasi kabutan (S) disebabkan oleh titik didih DME $\left(-25^{\circ} \mathrm{C}, 1 \mathrm{~atm}\right)$ yang jauh lebih rendah dari solar $\left(150-380^{\circ} \mathrm{C}, 1\right.$ atm), sehingga DME lebih mudah menguap dan cenderung mudah terdistribusi ke samping atau bergerak melebar.

Semakin tinggi tekanan injeksi akan memperkecil diameter butiran bahan bakar setelah injeksi (SMD) sehingga mempercepat penguapan dan proses pencampuran antara bahan bakar dan udara di dalam ruang bakar.

Semakin tinggi kandungan DME maka jarak penetrasi kabutan (S) akan semakin pendek, tingkat penguapan semakin cepat, sudut pengkabutan $\alpha$ semakin besar, proses pencampuran bahan bakar dan udara lebih sempurna sehingga pembakaran akan terjadi lebih sempurna, hal ini disebabkan oleh karena pembentukan uap lebih cepat dan lebih banyak pada awal pengkabutan.

\section{DAFTAR PUSTAKA}

Constantine Arcoumanis, 2008. Choongsik Bae, Roy Crookes, Eiji Kinoshita, The potential of di-methyl ether (DME) as an alternative fuel for compression ignition engines: $A$ review. Fuel, Volume 87, Issue 7, June 2008, p.10141030.
Elana M. Chapman, et all, 2003. Annual Technical Progress Report for Project Entitled, Impact of DME-Diesel Fuel Blend Properties on Diesel Fuel Injection Systems. May 16, 2002 - May 15, 2003, Report Issue Date: June 2003, The Energy Institute University Park, The Pennsylvania State University.

Hyun Kyu Suh, Chang Sik Lee, 2007. Experimental and analytical study on the spray characteristics of dimethyl ether (DME) and diesel fuels within a common-rail injection system in a diesel engine. EISEVIER, ScienceDirect, Mechanical Engineering, Hanyang University, 17 Haengdang-dong, Available on 5 July 2007.

Myung Yoon Kim, Seung Hyun Yoon, Bong Woo Ryu, Chang Sik Lee, 2008. Combustion and emsission characteristics of DME as an alternative fuel for compression ignition engines with a high pressure injection systems. Fuel, Volume 87, Issue 12, September 2008, p.2779-2786.

Troy A. Semelsberger, Rodney L. Borup, Howard L. Greene. 2006. Dimethyl ether (DME) as an alternative fuel. Journal of Power Sources, Volume 156, Issue 2, 1 June 2006, p.497511. 